\title{
Function and Manifestation of Decorative Color in Oil Painting Creation
}

\author{
Yuanming Zhang \\ Zhuhai College of Jilin University \\ Zhuhai, China
}

\begin{abstract}
Decorative color is a kind of decorative means and it decorates the described object correspondingly based on the painter's subjective feelings and aesthetic analysis. It falls into two aspects. First, painting works with decorative color generally show a kind of design consciousness and the second nature designed and created by it is similar to realistic painting works. Second, since it exists in life for a long time and even exists among the broad audience, it becomes the most ordinary kind of art. Decorative painting works attract people in all ages and even become the kind of form preferred by Chinese folk. This paper mainly introduces application of decorative color in oil painting creation, researches and analyzes application of decorative color in oil painting creation through the research on painting masters' works, analysis on them and comparisons among them, and sorts out some features of decorative color in oil painting creation, like flatness, exaggeration, personalization and symbolization. If painters pay more attention to presentation techniques, their train of thought for composition will be expanded to some extent.
\end{abstract}

Keywords-decorative color; oil painting creation; function; manifestation

\section{INTRODUCTION}

Decorative color has the imaginative beauty to make painting style prominent. Observing development history of oil painting, decorative color is always widely applied in oil painting works. Decorative style is accumulated in painting history for a long time and integrates artists' subjective emotion with aesthetic taste in painting. Generally speaking, decorative painting has concise and comprehensive basic features with strong expressive force. It abandons the tridimensional perspective method and uses drawn lines and spreads the color lump. Therefore, works seem to be innocent with decorative meaning. Colors in decorative painting are produced through combination of ideal colors and natural colors, paying more attention to generalizing colors.

\section{DeCORATIVE COlOR Plays A More AND MORE IMPORTANT ROLE IN OIL PAINTING CREATION}

People often call colors as the life of oil painting and color becomes the preferred language of oil painting. For example, in an art gallery, if we see an oil painting distantly, we will firstly be attracted by its colors before seeing the painting clearly. Under a preset color motif, the so-called strong color not only refers to bright colors. It consists of various different harmonious color elements. This kind of color contains vitality and visual impact, which can express the emotion inside the painting completely in the first time. Thus its attraction is the most persuasive. In oil painting creation, theories relevant to color have a long history. During the development of oil painting, especially modern painting, painters pay more attention to expressive force of color. Only rich color can make the painted object full Generation of impressionism (the transition of western modern arts) in 1883 is based on different understanding of color and classicism oil painting. It can totally prove the status of color in oil painting language. Development process of western art actually is the transformation process of the aesthetic ideal with color as the main display carrier of painting style. Oil creation develops from the passive depiction to reproduce the nature into using subjective colors to create the nature in the painter's heart. Application of color develops from the previous imitation of natural real color to subsequent subjective decorative color. Post-impressionist Cezanne's painting color has strong decorativeness. Later on, Picasso uses decorativeness of color as the one and only technique of color application in oil painting creation. As a painting language which can express painters' thoughts and feelings with certain aesthetic value, it expresses distinctive artistic performance, fully conforming to the main trend of oil painting creation's development. In modern oil painting creation, decorative color plays a main role.

\section{Features of DeCorative Color IN OIL Painting CREATION}

Compared with ordinary oil painting, oil painting with decorative color is unique to some extent in both color and modeling. Only by really understanding decorative color's features in oil painting, can we grasp its essence and fully give play to its function. First, the main feature displayed by oil painting decoration is complanation. The so-called complanation refers to using summarizing and concluding technique to present objective image and shape, displaying its smooth and concise modeling. When an object appears before us in a normal form, it usually has rich sense of depth in modeling, changing among relevant features of space, fiction and fact. As to color, conversion of conditional color is taken as color transference. These unique features are the elements pursued by many painting color sketches, aiming to display the essence collectively through doing subtraction to 
the simple way under the rich and complicated superficial phenomenon. Flat spreading technique is mostly used to do classification, summarization, extraction and proper deletion to the extra part, thus making the theme more outstanding, the image more typical and the color brighter. The displayed picture completely conforms to beauty in form. Second, colorific hue of the painting is clearer. The clearer hue endows the oil painting with stronger visual impact and expressive force. It properly gives full play to exaggeration, makes the theme effectively intensified, increases the painting's artistic appeal, gives better play to its artistic personality and enhances artistic emotions in a better way. Decorative color painting works do a series of color changing to the object in terms of color design, breaks the naturally existed spatial relation and innovates new visual effects of the painting. Of course, only those features emphasized by the painting can make the technique effective and significant. Symbolization highlights all features of decorative painting, which is the process of transforming objective images in the world into the simplest abstract symbolic elements, thus stimulating human's rich and concrete emotions and associations.

The image of decorative color itself is color, namely the basic feature of object color. Based on human's visual experience, when summarizing and abstracting colors, we find that red is red and green is green. Decorative color displays features which carry the nature of inherent color. There is balance in layout of decorative color, which is the objective requirement of form beauty. Balance is not average in area. It is the important feeling decorative color gives the mass audience. The feeling is symmetrical and light in weight. For example, strong and deep colors feel heavy while shallow and light colors feel light. Harmony can be achieved through balancing heavy and light colors. Decorative color boasts high purity. The so-called purity is brightness degree of color. Bright color totally conforms to the audience's aesthetic needs. In Matisse's Dance of the Still Life, a large area of blue serves as a foil to orange red, green and red, showing that decorative color itself contains a sense of beauty. Decorative color also has the nature of mobile observation. In the process of reflecting space, decorative color uses cavalier perspective, namely mobile observation, thus avoiding sheltering or overlapping due to the improper location and avoiding spatial limitation.

\section{EMBODIMENT OF DECORATIVE COLOR IN REPRESENTATIVE ARTISTS' WORK}

Application of decorative color in oil painting creation is not for the purpose of doing decorative painting. Application of decorative color expands oil painting color's visual and emotional manifestation area and it is an exploration on oil painting's unique language. Artists use colors as they like. Although colors they use have very high purity and hue, they coordinate well. Matisse, a maestro of brutalism, applies decorative color in typical and representative figure in oil painting creation. Each of his oil painting creations is a colorific trial. Through constantly intensifying features of "pure" and "simple", the painting has strong emotional stimulation. Red Harmony is one of the master works of
Matisse. The whole painting is in strong red. Looking at the fruit bowl and china bottle, we can feel that the painting at least has two spaces: horizontal and vertical, and front and back. However, Matisse uses the same red to show different spaces. It can be said that space is not the important point the creator wants to express. Colorific coordination of the blue picture and the figure's black clothes and yellow skin under the red style is the important point the creator wants to express. At that time, some traditional western painters don't like to use bright red or bright green, because they think those colors are brutal, lack colorific culture and fail to display the so-called "professional level". However, brutalism thinks that these bright red and bright green colors are the purest color, which can release the painter's emotion. The reason why those simple colors can release stronger power of internal emotion is simplicity of color. Matisse feels that these colors carrying a sense of mission can be persuasive to some extent and the painting gets closer to music because of performance of emotional color.

Amedeo Modigliani, an artist belonging to the school of Paris painting, is a passionate artist with distinct personality. His paintings pay more attention to pure colors and expressing the painter's deep emotion at one stretch. In terms of color decoration, his paintings are extremely free. In terms of the range of expression, his painting works are infinitely wide. In terms of the depth of expression, his works has certain generality and expressiveness.

Edouard Vuillard is another painter with strong representativeness. Different from Matisse's highly pure color comparison creating a strong visual impact, Vuillard's work is gentle and keeps a low profile. For example, in Garment Studio, one of his representative works, the ochre yellow color manifests luxury and honor of women of aristocratic stratum. Different figures' clothing color is highly summarized and abstracted and integrated into the painting uniformly. In terms of color, the painting highlights harmony among large color lumps. The background consists of medium gray cotton print and decorative patterns on the clothes correspond to the background. Embellishment of patterns increases decorativeness of the painting. We can also feel Japan's ukiyo-e prints and the Japanese screen style in Vuillard's works. The work mainly uses flat spreading and transition part between different color lumps is dealt with fine and delicate brushwork. Hidden brushwork makes decorative color's exquisiteness more prominent. It pays more attention to pureness, complanation, conceptualization and rhythmical sense, showing the unique charm. In the painting, plane figure consists of various kinds of colors, which is similar to the colorful tapestry consisting of many exquisite and beautiful patterns, having some decorative effects.

\section{SIGNIFICANCE OF DECORATIVE COLOR TO OIL PAINTING CREATION}

In daily creation, most painters emphasize how to draw complicated objects, and shaping light and shade and volume, thinking that superb technique displays "force and skill" and "professionalism". However, art is not completely about techniques. The sense of color formed after subjective 
processing and artistic processing of the painting displays the artist's artistic height more, because color is the soul of oil painting, showing the creator's aesthetic level and artistic talent. Decorative color sketch is mainly about transforming the three-dimensional space into two-dimensional space, thus objective space and the three-dimensional shape change the man-made complanation of subjective space. Through simplifying its appearance and evening out its volume, the original objects in different shapes can be changed into a kind of simple and clear symbol, which gives appreciators a whole understanding. In terms of color performance, the contract color or bright pure color close to the original color is used in the decoration style. Simple colors are used in flat spreading, making the painting clear and having certain modification. Color vision continuously reduces the authenticity, whose inevitable development trend is recognition of virtuality of color. Color vision has a great effect in composition of the painting. First, decorative painting uses two kinds of different hues, namely similar color and strong contrast color. It is easy for similar color to achieve visual unity and it produces weak chromatic aberration. Their comparison is similar to the comparison between colors of the same hue with different brightness and pureness. As long as matching properly with contrast color, the harmonious and unified effect will be achieved. Application of decorative color can make oil painting's individual features more evident, showing the side full of temperament and interest. Appreciators can be attracted by its emphasis on manifestation and intuition and its pursuit of visual beauty in the watching process. In general, integration of decorative color in oil painting creation gives play to its unique artistic characteristics to a great extent and shows its extremely attractive aspect. Some decorative elements are added to oil painting works, which can be counted as one of the greatly innovative means in terms of performance of oil painting.

\section{CONCLUSION}

Nowadays, people's aesthetic consciousness gets improved continuously. Decorative color's artistry and decorativeness satisfy modern people's direct emotional expression. People's different aesthetic views compel them to search for artistic styles different from the current situation. Decorative color in oil painting creation wins unprecedented attention. Modern artists often use decorative colors with a concise style in oil painting creation for embellishment. In terms of application of decorative color, from the previous objective color painting to impressionism, brutalism and nowadays, it has become one main element of performance. Liberation of color brings about liberation of people's feeling about color and comprehensive awakening appears. People have different aesthetic psychology in different periods and different styles and different periods should conform to different aesthetic psychology. Therefore we should constantly explore new oil painting language and search for new oil painting language from a new perspective. We should create decorative color paintings with unique national features according to our own life style, way of thinking and expression pattern.

\section{REFERENCES}

[1] Liu Yingying. Application of Decorative Color in Oil Painting Creation[J]. Popular Literature.

[2] Xue Xinyu. Analysis on Decorative Color Language in Oil Painting Creation[J]. Art Education Research

[3] Bao Ping. Analysis on Dunhuang Frescoes' Enlightenment on Oil Painting Creation[J]. Popular Literature.

[4] Zhong Zhenhuan. Discussion on Application of Guangxi Ethnic Folk Elements in Modern Oil Painting Creation[J]. Arts Circle.

[5] Wu Yao. Research on Application of Ethnic Costume in Oil Painting Creation[J]. Artistic Research. 